\title{
Suspected Locally Acquired Coccidioidomycosis in Human, Spokane, Washington, USA
}

Hanna N. Oltean, Mark Springer, Jolene R. Bowers, Riley Barnes, George Reid, Michael Valentine, David M. Engelthaler, Mitsuru Toda, Orion Z. McCotter

The full geographic range of coccidioidomycosis is unknown, although it is most likely expanding with environmental change. We report an apparently autochthonous coccidioidomycosis patient from Spokane, Washington, USA, a location to which Coccidioides spp. are not known to be endemic.

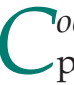

occidioides immitis is a rare but emerging fungal pathogen in Washington, USA; $<5$ autochthonous infections are reported annually (1). Coccidioidomycosis ranges from asymptomatic infection and mild pulmonary disease to potentially fatal severe disease $(2,3)$. Infection typically results from inhaling environmental arthroconidia (3-8).

Only the south-central region of Washington has been established as an area to which Coccidioides spp. are endemic; $C$. immitis has been detected in soil from Benton, Yakima, and Kittitas Counties (Figure). In addition, human and canine cases from local exposure have been reported from Franklin, Walla Walla, and Asotin Counties (8-10). Ecologic models predict a larger endemic area, but no models predict high endemicity in Spokane County $(11,12)$. We report a possible autochthonous coccidioidomycosis case from Spokane.

\section{The Study}

An 87-year-old woman came to an urgent care center because of a 4-day history of productive cough, fatigue, chest pain, and dyspnea. Chest radiography

\footnotetext{
Author affiliations: Washington State Department of Health, Shoreline, Washington, USA (H.N. Oltean); Spokane Regional Health District, Spokane, Washington, USA (M. Springer); Translational Genomics Research Institute, Flagstaff, Arizona, USA (J.R. Bowers, R. Barnes, G. Reid, M. Valentine, D.M. Engelthaler); Centers for Disease Control and Prevention, Atlanta, Georgia, USA (M. Toda, O.Z. McCotter)
}

DOI: https://doi.org/10.3201/eid2603.191536 showed right middle lobe pneumonia; levofloxacin was prescribed without further testing. Four days later (day 8 from symptom onset), she had worsening symptoms and an erythematous maculopapular rash. Antimicrobial drug therapy was switched to concurrent courses of azithromycin for 5 days and cephalexin for 10 days. Repeat chest radiography showed worsening pneumonia and a new pleural effusion. Follow-up visits documented persistent fatigue and productive cough. On day 49, repeat chest radiography showed new bilateral reticular opacities with mild peribronchial wall thickening but no evidence of pleural effusion or worsening infiltrates; a 7-day course of doxycycline was prescribed. Clinical improvement was noted 2 weeks later (day 66): there was resolution of cough, dyspnea, and chest pain.

On day 80 , she again had 4 days of congestion and productive cough and received a 5-day course of azithromycin. On day 89, she reported dyspnea, decreased appetite, and weight loss; an albuterol inhaler was prescribed. Three weeks later, she was given a diagnosis of a rectal adenocarcinoma detected by colonoscopy. Positron emission tomography scan (day 109) identified hypermetabolic activity, indicating a right lung mass, which was diagnosed as lung metastasis. A lung biopsy specimen of this mass (day 127) showed no malignant cells but documented spherules morphologically consistent with Coccidioides spp.

On day 137, an infectious disease consultant collected serum and prescribed fluconazole, noting pneumonia and 5 months of persistent symptoms consistent with coccidioidomycosis. Results of tests performed at the University of California Davis Serology Laboratory (Davis, CA, USA) (day 146) were positive for IgG and IgM by immunodiffusion and negative by complement fixation; these results were interpreted as indicating a primary coccidioidal infection not well focalized. 


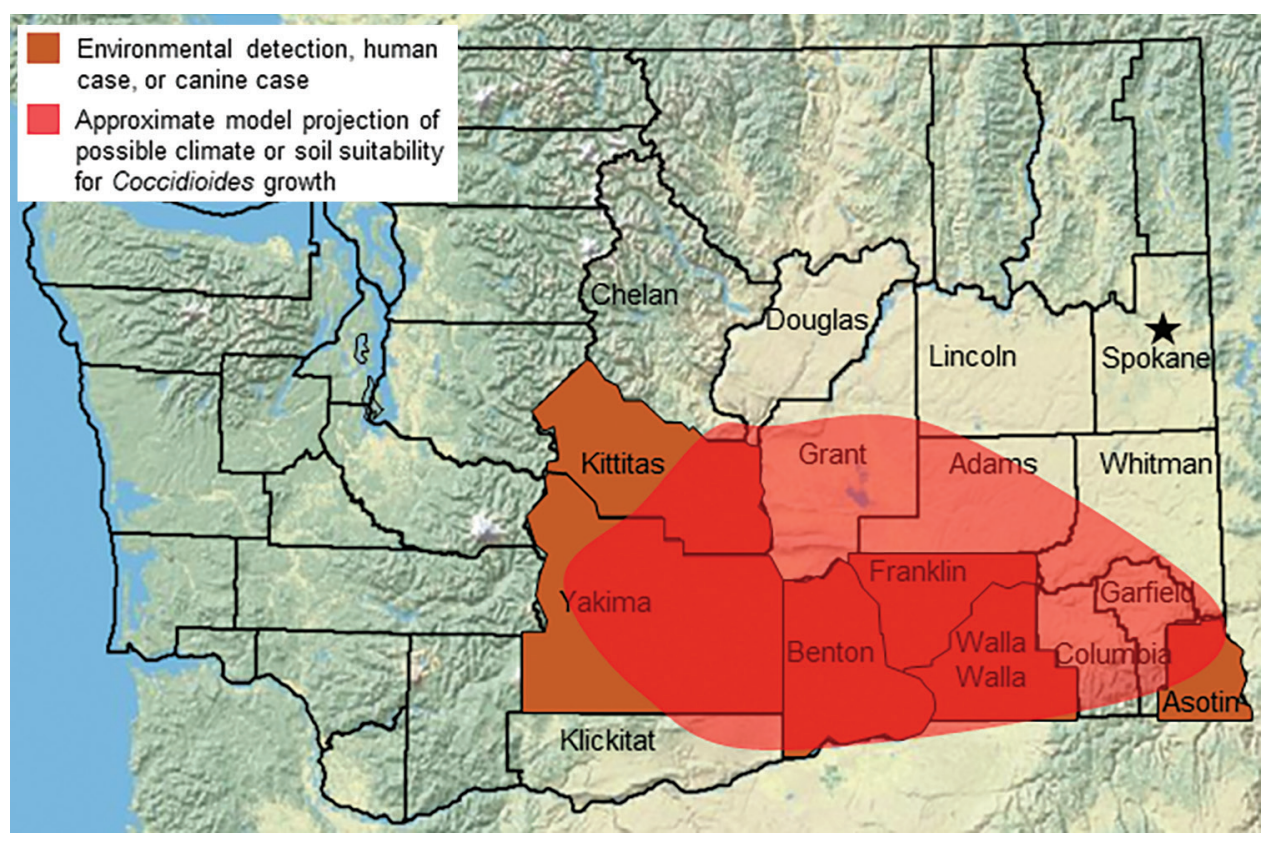

Figure. Known and suspected range of Coccidioides immitis in Washington, USA. Star indicates residence of case-patient with suspected locally acquired coccidioidomycosis.

Medical records for the patient indicated no recent travel to Coccidioides spp.-endemic areas, including south-central Washington. Three months of fluconazole therapy were completed; 13 months after her diagnosis, complement fixation remained negative and symptoms had resolved.

The case-patient was reported to Spokane Regional Health District on day 149. An in-person interview (day 178) elicited lifetime travel history, which included California ( 2 visits 15-20 years earlier), Oregon ( $>25$ years earlier), and southern Idaho ( $>3$ years earlier). She also reported travel within Washington, including Benton County (>8 years earlier) and Walla Walla County ( $>8$ years earlier). She reported contact with friends who had traveled to Arizona but denied receiving goods from their travel. Her only outdoor activities in the year before onset were nearby walks and scenic drives; she denied gardening or other soil exposures.

Her home was inspected for possible exposure sources, and building employees were interviewed regarding construction and landscaping. No specific exposures were identified; no new landscaping was identified; indoor plants were limited, and central air filters were regularly replaced. Road construction occurred nearby during her exposure period, which could represent a possible infection source.

Record review and patient interview medical history included iliopsoas corticosteroid injections for 2 years before onset; no other immunosuppressing conditions or medications were noted. Records indicated outpatient treatment for pneumonia in 2006 and hospitalization for pneumonia in 2011.
Fixed tissue from lung biopsy specimens was sent to Translational Genomics Research Institute (https://www.tgen.org), where we extracted DNA by using the GeneRead DNA Formalin-Fixed Paraffin-Embedded Kit (QIAGEN, https://www.qiagen. com). We identified Coccidioides spp. by using quantitative PCR, as described $(9,13)$. We performed amplicon sequencing targeting the quantitative PCR region and 10 distinct canonical single-nucleotide polymorphisms (canSNPs) that define the previously described Washington clade (10). Sequence reads aligned with the quantitative PCR target at $1,900 \times$ depth of coverage, and reads aligned with 2 canSNP targets, at $10 \times$ and $6 \times$ depth, both suggesting that the sample fits within the Washington C. immitis clade. The genomic regions containing the remaining canSNPs had no coverage in these metagenomic samples, limiting a high degree of confidence for true phylogenetic placement.

\section{Conclusions}

We report an apparently autochthonous case of coccidioidomycosis in a woman from Spokane, Washington, a location not known to have Coccidioides spp. This patient had many clinical setbacks commonly described with coccidioidomycosis, including 5 unsuccessful antibacterial courses, misdiagnosed lung cancer, and 131 days of healthcare encounters before an accurate diagnosis was obtained.

At least 4 possible hypotheses could explain how this patient became infected. Coccidioides infections might be asymptomatic or involve subclinical 
disease until a reactivation occurs, typically after immunosuppression. First, she could have been infected during travel to south-central Washington (>8 years earlier). Findings of canSNPs matching the known Washington clade support this hypothesis. Second, infection could have occurred during travel to California reported $>15$ years before onset, although the SNP analysis does not support this hypothesis. The negative complement fixation and positive IgM results suggest more recent infection (14), which, along with no calcified lesions observed by chest radiography, would argue against reactivation of infection acquired during previous travel. Third, she could have been exposed through fomite transmission, which has been described (15). The patient had visitors who traveled to Arizona; however, no gifts or goods were brought back, and C. posadasii would be expected in fomites from Arizona. Plants or soil purchased from another diseaseendemic area around her residence are hypothetical sources of exposure, although none were identified. Fourth, it is possible that exposure happened locally in Spokane. Nearby road construction in the weeks before symptom onset could represent a possible source. However, coccidioidomycosis exposures have not been reported from Spokane, and ecologic niche models predict low likelihood of Coccidioides habitat (12). The nearest known location of detection of Coccidioides spp. in soil was $\approx 130$ miles from Spokane. Windborne spores from south-central Washington or through fomite transmission from intrastate commerce or visitors are alternative possibilities. Sequence alignment with 2 canSNP targets and laboratory findings consistent with primary disease support a hypothesis of recent exposure to the Washington clade.

Recent exposure in Spokane County is the most plausible explanation of illness. However, clear documentation of Coccidioides spp. endemicity in Spokane will require additional clinical cases or environmental detections.

The environmental range of Coccidioides spp. is not fully understood, and is possibly expanding in arid climates (11). This possible expansion creates a diagnosis and surveillance challenge because raising and maintaining clinical awareness in low-incidence or emerging settings is difficult. Although determining a definitive exposure source for this case-patient is not possible, the potential for coccidioidomycosis acquisition in new locations cannot be ignored.

Healthcare providers should consider the risk for coccidioidomycosis in patients who reside in or travel to Coccidioides-endemic regions (3). In addition, healthcare providers should consider fungal infections in patients who have respiratory symptoms that do not respond to antibacterial therapy and should be aware that the geographic risk for coccidioidomycosis is evolving. Ongoing public health surveillance is required to clarify the range of Coccidioides spp. and to improve messaging to healthcare providers and the public.

\section{Acknowledgments}

We thank Marcia Goldoft, Tom Chiller, and Brendan R. Jackson for critically reviewing the manuscript.

\section{About the Author}

Ms. Oltean is the zoonotic and vectorborne disease epidemiologist for the Washington State Department of Health, in the Office of Communicable Disease Epidemiology, Shoreline, WA. Her primary research interests are design, implementation, and evaluation of zoonotic disease surveillance systems.

\section{References}

1. Washington State Department of Health. Washington State communicable disease report, 2017 [cited 2019 Dec16]. https:/ / www.doh.wa.gov/Portals/1/Documents/5100/ 420-004-CDAnnualReport2017.pdf

2. Brown J, Benedict K, Park BJ, Thompson GR III. Coccidioidomycosis: epidemiology. Clin Epidemiol. 2013;5:185-97.

3. Valley Fever Center for Excellence, The University of Arizona. Valley fever (coccidioidomycosis) tutorial for primary care professionals, 2015 [cited 2019 Dec 16]. http://vfce.arizona.edu/sites/vfce/files/tutorial_for_ primary_care_professionals_1.pdf

4. Cordeiro RA, Brilhante RSN, Rocha MFG, Bandeira SP, Fechine MAB, de Camargo ZP, et al. Twelve years of coccidioidomycosis in Ceará State, northeast Brazil: epidemiologic and diagnostic aspects. Diagn Microbiol Infect Dis. 2010;66:65-72. https:// doi.org/10.1016/ j.diagmicrobio.2008.09.016

5. Wilken JA, Sondermeyer G, Shusterman D, McNary J, Vugia DJ, McDowell A, et al. Coccidioidomycosis among workers constructing solar power farms, California, USA, 2011-2014. Emerg Infect Dis. 2015;21:1997-2005. https://doi.org/10.3201/eid2111.150129

6. Pappagianis D; Coccidioidomycosis Serology Laboratory. Coccidioidomycosis in California state correctional institutions. Ann N Y Acad Sci. 2007;1111:103-11. https://doi.org/10.1196/annals.1406.011

7. Colson AJ, Vredenburgh L, Guevara RE, Rangel NP, Kloock CT, Lauer A. Large-scale land development, fugitive dust, and increased coccidioidomycosis incidence in the Antelope Valley of California, 1999-2014. Mycopathologia. 2017;182:439-58. https://doi.org/10.1007/s11046016-0105-5

8. Marsden-Haug N, Goldoft M, Ralston C, Limaye AP, Chua J, Hill H, et al. Coccidioidomycosis acquired in Washington State. Clin Infect Dis. 2013;56:847-50. https://doi.org/10.1093/cid/cis1028 
9. Litvintseva AP, Marsden-Haug N, Hurst S, Hill H, Gade L, Driebe EM, et al. Valley fever: finding new places for an old disease: Coccidioides immitis found in Washington State soil associated with recent human infection. Clin Infect Dis. 2015;60:e1-3. https:/ / doi.org/10.1093/cid/ ciu681

10. Oltean HN, Etienne KA, Roe CC, Gade L, McCotter OZ, Engelthaler DM, et al. Utility of whole-genome sequencing to ascertain locally acquired cases of coccidioidomycosis, Washington, USA. Emerg Infect Dis. 2019;25:501-6. https://doi.org/10.3201/eid2503.181155

11. Gorris ME, Treseder KK, Zender CS, Randerson JT. Expansion of coccidioidomycosis endemic regions in the United States in response to climate change. GeoHealth. 2019;3:308-27. https://doi.org/10.1029/2019GH000209

12. Dobos R, McCotter O. Modeling and mapping of Coccidioides soil habitat. In: Proceedings of the 61st Annual Coccidioidomycosis Study Group Meeting, Stanford, California, 2017 Aug 10-13. Stanford (CA): 2017 [cited 2019
Dec 27]. http:/ / coccistudygroup.com/wp-content/uploads /2017/11/CSG-61st-Annual-Proceedings-11-27-17.pdf

13. Bowers JR, Parise KL, Kelley EJ, Lemmer D, Schupp JM, Driebe EM, et al. Direct detection of coccidioides from Arizona soils using CocciENV, a highly sensitive and specific real-time PCR assay. Med Mycol. 2019;57:246-55 https://doi.org/10.1093/mmy/myy007

14. Pappagianis D, Zimmer BL. Serology of coccidioidomycosis Clin Microbiol Rev. 1990;3:247-68. https:/ / doi.org/10.1128/ CMR.3.3.247

15. Stagliano D, Epstein J, Hickey P. Fomite-transmitted coccidioidomycosis in an immunocompromised child. Pediatr Infect Dis J. 2007;26:454-6. https:/ / doi.org/ 10.1097/01.inf.0000259231.95285.bc

Address for correspondence: Hanna N. Oltean, Washington State Department of Health, 1610 NE 150th St, Shoreline, WA 98155,

USA; email: hanna.oltean@doh.wa.gov

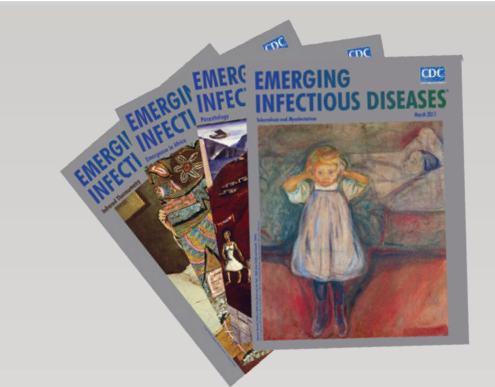

- Epidemiology of Mycobacterium bovis Disease in Humans in England, Wales, and Northern Ireland, 2002-2014

- Three Cases of Neurologic Syndrome Caused by DonorDerived Microsporidiosis

- Epidemiology of Invasive Haemophilus influenzae Disease, Europe, 2007-2014

- Zika Virus RNA Replication and Persistence in Brain and Placental Tissue

- Spatiotemporal Fluctuations and Triggers of Ebola Virus Spillover

- New Mycobacterium tuberculosis Complex Sublineage, Brazzaville, Congo

- Whole-Genome Analysis of Bartonella ancashensis, a Novel Pathogen Causing Verruga Peruana, Rural Ancash Region, Peru

- Epidemiology of Nontuberculous Mycobacterial Lung Disease and Tuberculosis, Hawaii, USA

- Mycobacterium tuberculosis Transmission among Elderly Persons, Yamagata Prefecture, Japan, 2009-2015

- Comparison of Sputum-Culture Conversion for Mycobacterium bovis and M. tuberculosis

- Genetically Diverse Filoviruses in Rousettus and Eonycteris spp. Bats, China, 2009 and 2015

- Use of Mass-Participation Outdoor Events to Assess Human Exposure to Tickborne Pathogens

\section{March 2017}

\section{Tuberculosis and Mycobacteria}

- Pulmonary Nontuberculous Mycobacteria-Associated Deaths, Ontario, Canada, 2001-2013

- Variegated Squirrel Bornavirus 1 in Squirrels, Germany and the Netherlands

- Molecular, Spatial, and Field Epidemiology Suggesting TB Transmission in Community, Not Hospital,

Gaborone, Botswana

- pncA Gene Mutations Associated with Pyrazinamide Resistance in Drug-Resistant Tuberculosis, South Africa and Georgia

- Increase in Tuberculosis Cases among Prisoners, Brazil, 2009-2014

- Likely Autochthonous Transmission of Trypanosoma cruzi to Humans, South Central Texas, USA

- Mycobacterium tuberculosis in Wild Asian Elephants, Southern India

- Rhodococcus Infection in Solid Organ and Hematopoietic Stem Cell Transplant Recipients

- Mycobacterium tuberculosis Infection among Asian Elephants in Captivity

- Molecular Evidence of Drug Resistance in Asymptomatic Malaria Infections, Myanmar, 2015

- Pneumonic Plague Transmission, Moramanga, Madagascar, 2015 